\title{
Electro-Disinfection of Municipal Wastewater: Laboratory Scale Comparison between Direct Current and Alternating Current
}

\author{
Enrique J. La Motta*, Guillermo J. Rincón**, Julio Acosta***, Xavier \\ Chávez**** \\ *(Department of Civil and Environmental Engineering, University of New Orleans, USA \\ **(Department of Civil and Environmental Engineering, University of New Orleans, USA \\ ***(Faculty of Engineering on Earth Sciences, ESPOL, Guayaquil, Ecuador \\ ****(Department of Public Works, New Orleans, LA, USA
}

\begin{abstract}
Electrodisinfection of wastewater has been investigated extensively in the past, although a consensus over the use of direct current (DC) or alternating current (AC) as the most efficient electricity source has not been reached to date. The research presented herein compares the use of DC and AC in electrodisinfection of municipal wastewater aiming to provide conclusive evidence on the benefits of using one type of current over the other. During the experimental phase, a bench-scale electrodisinfection reactor equipped with iridium oxidecoated titanium electrodes was operated continuously, and E.coli inactivation, free and total chlorine generation were measured. The results observed indicate that, under the experimental conditions, DC represents a more efficient and economical alternative to electrodisinfection than AC.
\end{abstract}

Keywords - Electro-d isinfection, alternating current, direct current, wastewater treatment.

\section{INTRODUCTION}

The main advantage of the electrodisinfection process is the production of disinfection conditions in situ within the treatment device, thus avoiding the drawbacks normally associated with adding disinfectants, such as transport and storage of dangerous chemical compounds. Additional advantages over other conventional disinfection technologies include environmental compatibility, versatility, energy efficiency, safety, selectivity, amenability to automation, and cost effectiveness [1].

In spite of these advantages, electrodisinfection faces, as an emerging technology, several challenges to being fully accepted for large scale treatment: electrode materials may be prone to erosion, complexation, oxidation, wearing, or inactivation; the best electrode materials frequently involve precious metals, and this increases costs; the lack of knowledge or understanding of electrochemistry is perhaps the greatest barrier for its utilization [2].

As early as 1887 , patents describing a method for treating sewage by mixing it with seawater and electrolyzing this mixture were granted in the UK and France [3]. Two treatment plants utilizing such a technology described in these patents were built in 1889 in England and operated for ten years. Iron electrodes were used, and seawater was added as a chlorine source for disinfection.
In the U.S., electrolytic sludge treatment plants operated in California and Oklahoma since 1911, using steel electrodes alternatively connected to the positive and negative terminals of a direct current (DC) power supply, and all were praised for their high-quality effluent and lack of odor. However, operation costs were high since ferric hydroxide sludge generated by the dissolution of the steel electrodes, collected at the settling tanks, had to be hauled away. Eventually, all plants were abandoned in 1930 [3].

Common electrode materials used in electrodisinfection reactors include stainless steel, aluminum, graphite, carbon-cloth, titanium, platinum, and diamond. Disinfection efficiency has improved by coating the anode surface with ruthenium oxide $\left(\mathrm{RuO}_{2}\right)$, mixed iridium oxide (MIO), and/or titanium oxide $\left(\mathrm{TiO}_{2}\right)$, because this coating makes the anode highly resistant to corrosion and improves the production of disinfecting species [4].

Modern ballast water electro-disinfection units, for example, take advantage of the high chloride ions and salts concentrations present in seawater to develop free chlorine species to promote disinfection [5]. In this case, hypochlorous acid species are the leading disinfectant species, and the treated water will have both residual chlorine and disinfection by-products. Chlorine is chemically produced at the anode from chlorides present in water [6]. The process has been summarized as follows $[4,7]$ : 
$2 \mathrm{Cl}^{-} \rightarrow \mathrm{Cl}_{2}+2 \mathrm{e}^{-}$

$\mathrm{Cl}_{2}+\mathrm{H}_{2} \mathrm{O} \leftrightarrows \mathrm{HOCl}+\mathrm{H}^{+}+\mathrm{Cl}^{-}$

$\mathrm{HOCl} \leftrightarrows \mathrm{ClO}^{-}+\mathrm{H}^{+}$

By using anodes with a high oxygen overvoltage, high current density, and low water temperature, ozone can be generated at the anode, and hydrogen peroxide may also be produced at the cathode:

$$
\begin{aligned}
& 3 \mathrm{H}_{2} \mathrm{O} \rightarrow \mathrm{O}_{3}+6 \mathrm{e}^{-}+6 \mathrm{H}^{+} \\
& \mathrm{O}_{2}+2 \mathrm{H}_{2} \mathrm{O}+2 \mathrm{e}^{-} \rightarrow \mathrm{H}_{2} \mathrm{O}_{2}+2 \mathrm{OH}^{-}
\end{aligned}
$$

Some technologies have been developed specifically to avoid hydrogen production and focus on hydroxyl ions generation as described in (6) [4]:

$\mathrm{O}_{2}+2 \mathrm{H}_{2} \mathrm{O}+4 \mathrm{e}^{-} \rightarrow 4 \mathrm{OH}^{-}$

Another important characteristic of electrochemical disinfection reactions is that the generation of disinfectant byproducts is less than in conventional chlorination [8].

Research performed at the University of New Orleans on synthetic ballast water electrodisinfection [9], demonstrated that killing of bacteria took place when using DC, even in the absence of chlorides.

As an alternative to using chlorine as a disinfectant, or DC-driven electrodisinfection, the use of alternating current (AC) may substantially decrease the generation of free chlorine. In this case the AC polarity alternates periodically, which results in less electrolysis, and consequently, lower generation of chlorine [10]. Other researchers [11, 12] were able to obtaining efficient disinfection of zero-chloride water using AC. Barashkov, et al. [12] claimed that disinfection was achieved due to the generation of hydroxyl radicals $(\bullet \mathrm{OH})$ and other intermediate highly active anion radicals $\left(\bullet^{\circ} \mathrm{O}_{2}{ }^{-}\right.$.

Several investigators claim that free chlorine does not appear to be the main disinfecting agent in electrodisinfection [13]. Instead, these authors have found that the production of more powerful (than chlorine) microorganis $\mathrm{m}$ killing agents, such as $\mathrm{H}_{2} \mathrm{O}_{2},[\mathrm{O}], \cdot \mathrm{OH}$, and $\cdot \mathrm{HO}_{2}$, is what provides the high degree of disinfection observed in their experimental trials. Also, the bactericidal efficiency of the process generally increases when the retention time and current density are increased [14].

The existing literature on electrodisinfection is not conclusive on whether using DC or AC is more advantageous from the operational and economic standpoint. Moreover, a non-measurable total chlorine concentration of less than $0.1 \mathrm{mg} / \mathrm{L}$ is now required by the USEPA in secondary effluents (LPDES File Number LA0042048). Therefore, given these constrains, the main objective of this research is to compare both technologies to determine whether the use AC or DC is the most appropriate alternative for electrodisinfection treatment. A comparis on of DC and AC is carried out by means of laboratory-scale experiments where operational parameters such as electrodes material, residence time, current density, power consumption, and salinity of the wastewater are analyzed to derive the disinfection efficiency corres ponding to each of the evaluated alternatives.

\section{EXPERIMENTAL PHASE}

Wastewater collected from the effluent channel of one of the secondary clarifiers at the Marrero Wastewater Treatment Plant, in Marrero, LA, was used as the experimental fluid.

Determination of $E$. coli in the samples was done according to EPA Method 1603. Initial chlorine concentration was found using the Hach Chloride Test Kit, Model 8-P, while post-treatment free and total chlorine were determined by Hach Methods 10231 and 10232, respectively, using Hach TNT867 ampules and a Hach DR-5000 spectrophotometer.

The electrodisinfection reactors, shown in Figure 1, consisted of proprietary units made by Ecolotron, Inc. These reactors exhibit a plate and frame design and can be tightly closed mechanically. The plates are individually separated by recessed, gasketed, nonconductive spacer plates, which completely enclose and isolate all fluids, electrical contact points, and electrodes within the reactor structure [15]. This reactor configuration allows to modify not only the cell volume by altering electrode spacing, but also the number of electrode plates and the liquid flow rate.

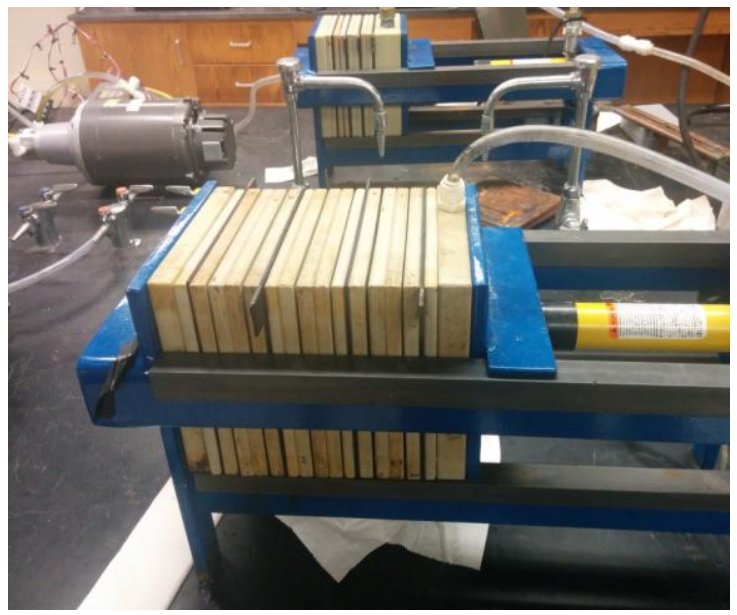

Figure 1. Bench-scale electrodisinfection reactor 
The components of a typical electrodisinfection cell, as assembled for the electrodisinfection experiments, are shown in Figure 2.

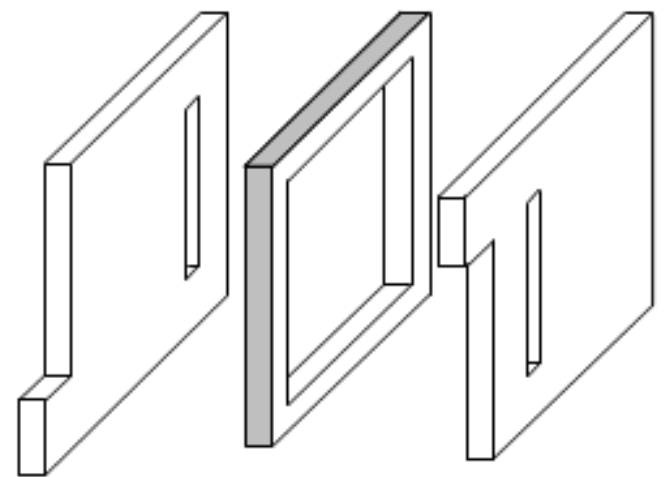

Figure 2. Components of an electrodisinfection cell including electrode plates with vertical slots and rubber gasket. (Rincon et al., 2013)

A BK Precision High Current DC-regulated Power 1791 supplied direct current to the reactor. This apparatus allowed for selecting either the current intensity or the voltage applied.

The alternating current power supply consisted of a Variac Variable Transformer, 300 VA Max, 0-130 V Output and $3 \mathrm{~A}$, and was used to regulate the voltage and indirectly the current flowing through the system. A three-prong plug was connected to the output of the power supply and alligator clamps were connected to the positive and negative wires; a banana plug was connected to the ground wire which, in turn, was connected to the ground of the wall power outlet. Since the wires used were less than $3.2 \mathrm{~mm}$ in diameter and less than $2 \mathrm{~m}$ in length, the loss of electricity was considered negligible. The voltage input necessary to get the desired current intensity depended on the number of electrodes connected to the power supply, that is, the more the electrodes connected, the lower the voltage and the higher the current.

To keep the wastewater completely mixed, before, during and after the tests, a $0.19-\mathrm{m}^{3}(50-$ gallon) tank with a mechanical stirrer was used. The tank was placed at a higher level than the reactors, and the latter were feed by gravity flow. A needle valve was attached on the effluent side of the reactor to regulate the flow rate. Because the flow varied with the water level on the tank, the needle valve was constantly adjusted to keep constant flow rate.

\subsection{Electrodisinfection experiments using direct current}

Table 1 presents a summary of the operational parameters of the electrodisinfection reactor for each one of the DC-experiments performed. Voltage, current intensity, electrodes configuration and number, effective reactor volume, and flow rate were modified between runs in an attempt to find the optimum parameters combination for highest disinfection efficiency.

Table 1. Su mmary of operational para meters in electrodisinfection experiments using direct current.

\begin{tabular}{|c|c|c|c|c|c|c|c|}
\hline$\underset{\Xi}{\Xi}$ & 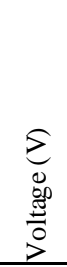 & 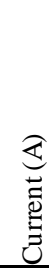 & $\begin{array}{l}\frac{0}{0} \\
\sum_{00}^{0} \\
.0 \\
0 \\
0 \\
0 \\
0\end{array}$ & 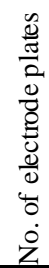 & 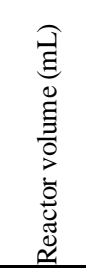 & 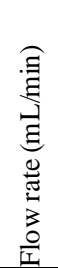 & 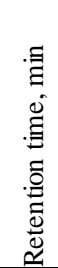 \\
\hline $1 \mathrm{~A}$ & 59.7 & 0.6 & MP & 2 & 1040 & 100 & 10.4 \\
\hline $2 \mathrm{~A}$ & 47 & 0.4 & MP & 2 & 1040 & 100 & 10.4 \\
\hline $3 \mathrm{~A}$ & 28.5 & 0.2 & MP & 2 & 1040 & 100 & 10.4 \\
\hline $5 \mathrm{~A}$ & 36 & 0.4 & MP & 2 & 1040 & 100 & 10.4 \\
\hline $4 \mathrm{~A}$ & 54 & 0.6 & MP & 2 & 1040 & 100 & 10.4 \\
\hline $6 \mathrm{~A}$ & 40 & 0.5 & $\mathrm{BP}$ & 4 & 700 & 70 & 10 \\
\hline $7 \mathrm{~A}$ & 40 & 0.5 & $\mathrm{BP}$ & 4 & 700 & 140 & 5 \\
\hline $1 \mathrm{~B}$ & 9.5 & 0.6 & MP & 4 & 1070 & 100 & 10.7 \\
\hline $2 \mathrm{~B}$ & 7.9 & 0.4 & $\mathrm{MP}$ & 4 & 1070 & 100 & 10.7 \\
\hline $3 \mathrm{~B}$ & 6.4 & 0.2 & MP & 4 & 1070 & 100 & 10.7 \\
\hline $4 \mathrm{~B}$ & 51 & 0.4 & BP & 4 & 1070 & 100 & 10.7 \\
\hline $5 \mathrm{~B}$ & 65.1 & 0.5 & $\mathrm{BP}$ & 4 & 1070 & 100 & 10.7 \\
\hline $6 \mathrm{~B}$ & 65 & 0.3 & BP & 4 & 1730 & 172 & 10.1 \\
\hline $7 \mathrm{~B}$ & 65 & 0.3 & BP & 4 & 17230 & 344 & 5 \\
\hline
\end{tabular}

Chlorides, free chlorine and total chlorine were measured before and immediately after treatment; and in some cases the treated effluent was kept in a completely mixed chamber, from which both free and total chlorine were measured every 10 minutes for up to 40 minutes in order to determine the rate of chlorine decay.

As noted in Table 1, experiments were run with the reactor connected in either monopolar or bipolar mode. Under the bipolar configuration only the external electrodes are connected, while the inner electrodes acquire a polarity opposite to that of the closest connected electrode and a potential corresponding to a proportional fraction of the overall cell voltage, thus reducing power requirements [1]. This configuration is expected to yield higher disinfection efficiency than the monopolar one, in which all the electrodes are connected to the power source.

\subsection{Electrodisinfection experiments using alternating current}

Similar to the electrodisinfection experiments with $\mathrm{DC}$, in the $\mathrm{AC}$ experiments, the number of electrodes, reactor retention time and flow rate were changed for different runs.

In a typical $\mathrm{AC}$ experiment, after at least two-and-one-half retention times of flow equivalent through the reactor, three samples were taken for 
bacterial count purposes and another sample was taken for chlorides and chlorine testing. Table 2 presents a summary of the experiments run using $\mathrm{AC}$ and their operational parameters.

\section{RESULTS AND DISCUSSION}

\subsection{DC-Electrodisinfection Results}

Table 3 shows the results of the DC experiments detailed on Table 1. Since the reactor configuration was changed for the different DC experiments, the resulting power consumption also varied in every case. For this reason, the energy usage per unit volume was calculated for each run in order to be able to extrapolate operational cost of treatment to large scale electrodisinfection systems under similar operational conditions. Multiplying the energy consumption per liter of treated effluent by the average industrial power cost of 0.0738 $\$ / \mathrm{kWh}$ results in the data presented in Table 4.

Table 2. Summary of operational parameters in electrodisinfection experiments using alternating current

\begin{tabular}{|c|c|c|c|c|c|c|c|}
\hline$\Xi$ & $\begin{array}{l}\sum \\
0 \\
00 \\
\frac{ \pm}{0} \\
0 \\
1\end{array}$ & 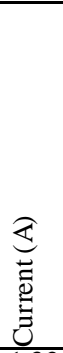 & 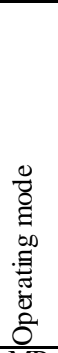 & 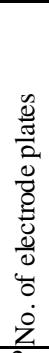 & 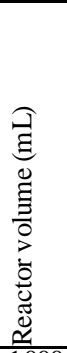 & 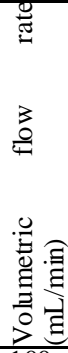 & 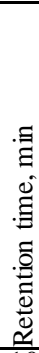 \\
\hline 1 & 130 & 1.32 & MP & 2 & 1000 & 100 & 10 \\
\hline 2 & 35 & 2.1 & MP & 3 & 800 & 100 & 8 \\
\hline 3 & 55 & 2.7 & MP & 3 & 800 & 33.3 & 24 \\
\hline 4 & 6 & 2.7 & MP & 6 & 670 & 33.7 & 20 \\
\hline 5 & 6 & 2.6 & MP & 6 & 670 & 16 & 42 \\
\hline 6 & 10.7 & 2.6 & MP & 5 & - & - & 29 \\
\hline 7 & 23.8 & 2.6 & MP & 4 & 410 & 18 & 23 \\
\hline 8 & 40 & 3 & MP & 3 & 780 & 78 & 10 \\
\hline 9 & 40 & 3.4 & MP & 3 & 780 & 26 & 30 \\
\hline 10 & 132.1 & 1.6 & $\mathrm{BP}$ & 4 & - & - & 10 \\
\hline
\end{tabular}

The cost of treatment varies depending on the configuration used. The minimum amount of energy consumed, while providing the required 5$\log$ disinfection efficiency, corresponds to runs $1 \mathrm{~B}$ and $7 \mathrm{~B}$, both with an operational cost of around $\$ 0.070$ per $\mathrm{m}^{3}$. Run $1 \mathrm{~B}$ has the added advantage of having generated a very low free residual chlorine concentration, which would make post-treatment de-chlorination unnecessary.

\subsection{Chlorine Dissipation/Decay in DC electrodisinfection treatment}

Dissipation of residual chlorine in the treated effluent followed typical exponential decay kinetics. Non-linear regression of these observations, obtained by extended sampling of post-treatment samples, results in Eq. 7.

$$
\frac{C l_{2, R}}{C l_{2, R_{0}}}=0.949 e^{0.361 t}
$$

Where $\mathrm{Cl}_{2, \mathrm{R}} / \mathrm{Cl}_{2, \mathrm{R}_{0}}$ is the fraction of total residual chlorine, and $\mathrm{t}$ is the time in hours. Using this expression, if the time of flow from the point of application of electro-chlorination to the point of discharge to the receiving stream is around $4.36 \mathrm{~h}$

Table 3. Electrodisinfection efficiency, and total and free chlorine concentrations in DC experiments

\begin{tabular}{|c|c|c|c|c|c|c|c|}
\hline Run & $\begin{array}{l}\text { Sample } \\
\text { volume for } \\
\text { intital } \\
\text { colony } \\
\text { count (mL) }\end{array}$ & 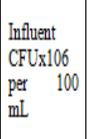 & $\begin{array}{l}\text { Sample } \\
\text { volume for } \\
\text { effluent } \\
\text { colony } \\
\text { count (mL) }\end{array}$ & $\begin{array}{l}\text { Effluent } \\
\text { CFUx } 10^{-6} \\
\text { per } 100 \mathrm{~mL}\end{array}$ & \begin{tabular}{|l} 
Free \\
residual \\
chlorine, \\
mgL
\end{tabular} & $\begin{array}{l}\text { Total } \\
\text { Residual } \\
\text { Chlorime, } \\
\text { mgL }\end{array}$ & Log removal \\
\hline $1 \mathrm{~A}$ & 0.002 & 2.5 & 0.002 & 0 & 0.56 & & $>6$ \\
\hline $2 \mathrm{~A}$ & 0.002 & 1.6 & 0.002 & 0 & 0 & & $>6$ \\
\hline $3 \mathrm{~A}$ & 0.002 & 1.6 & 0.002 & $\sim 0.017$ & 0 & & 2 \\
\hline $4 \mathrm{~A}$ & 10 & 1.8 & 0.002 & Very high & 0 & & 0 \\
\hline $5 \mathrm{~A}$ & 10 & 1.8 & 0.002 & Very high & 0.21 & & 0 \\
\hline $6 \mathrm{~A}$ & 10 & 1.8 & 0.002 & 0 & \begin{tabular}{|l|}
1.34 \\
\end{tabular} & & $>6$ \\
\hline $7 \mathrm{~A}$ & 10 & 1.8 & 0.002 & 0 & \begin{tabular}{|l|}
0.39 \\
\end{tabular} & 0.81 & $>6$ \\
\hline $1 \mathrm{~B}$ & 0.002 & 2.5 & 0.002 & 0 & 0.1 & & $>6$ \\
\hline $2 B$ & 0.002 & \begin{tabular}{|l|}
1.6 \\
\end{tabular} & 0.002 & \begin{tabular}{|l|}
$\sim 1.7$ \\
\end{tabular} & 0 & & 0 \\
\hline $3 \mathrm{~B}$ & 0.002 & \begin{tabular}{|l|}
1.6 \\
\end{tabular} & 0.002 & \begin{tabular}{|l|}
$\sim 1.5$ \\
\end{tabular} & 0 & & 0 \\
\hline$A B$ & 10 & 1.8 & 10 & \begin{tabular}{|l|l}
$\sim 1600$ \\
\end{tabular} & 0 & & \begin{tabular}{|l|}
23 \\
\end{tabular} \\
\hline $5 \mathrm{~B}$ & 10 & 1.8 & 10 & $\sim 0.00003$ & 0.35 & 0.84 & $>6$ \\
\hline $6 \mathrm{~B}$ & 10 & \begin{tabular}{|l|}
1.8 \\
\end{tabular} & 10 & 0 & 0.06 & 0.14 & 36 \\
\hline $7 \mathrm{~B}$ & 10 & 1.8 & 10 & 0 & \begin{tabular}{|l|}
0.39 \\
\end{tabular} & 0.08 & $>6$ \\
\hline
\end{tabular}

Table 4. Energy consumption and treatment cost of DC electrod isinfection.

\begin{tabular}{|l|l|l|}
\hline Run & Energy, $\mathrm{kWh} / \mathrm{Lx} 10^{4}$ & Cost, $\$ / \mathrm{m}^{3}$ \\
\hline 3B & 2.13 & 0.0157 \\
\hline 2B & 5.27 & 0.0389 \\
\hline 7B & 9.45 & 0.0697 \\
\hline 1B & 9.5 & 0.0701 \\
\hline 3A & 9.5 & 0.0701 \\
\hline 2SS & 17.3 & 0.128 \\
\hline 6B & 18.9 & 0.14 \\
\hline 7A & 23.8 & 0.176 \\
\hline 4A & 24 & 0.177 \\
\hline 1SS & 28.8 & 0.212 \\
\hline 2A & 31.3 & 0.231 \\
\hline 4B & 34 & 0.251 \\
\hline 6A & 47.6 & 0.351 \\
\hline 5A & 54 & 0.399 \\
\hline 5B & 54.3 & 0.4 \\
\hline 1A & 59.7 & 0.441 \\
\hline
\end{tabular}

in order not to exceed the maximum total chlorine concentration stipulated by the LPDES $(0.1 \mathrm{mg} / \mathrm{L})$, the total residual concentration after the electrochlorination reactor should be less than $0.5 \mathrm{mg} / \mathrm{L}$.

\subsection{AC-Electrodisinfection Results}

Table 5 shows a summary of the disinfection efficiencies achieved by the experiments described in Table 2. The disinfection efficiency for runs 1,8 
and 10 are reported as low, meaning that disinfection in these cases was negligible. Effluent temperature was not recorded in every case.

Table 5. Electrodisinfection efficiency in AC experiments

\begin{tabular}{|l|l|l|}
\hline Run & $\begin{array}{l}\text { Effluent } \\
\text { Temperature }\end{array}$ & Log removal \\
\hline 1 & - & 0 \\
\hline 2 & - & 0.9 \\
\hline 3 & 41 & 1.4 \\
\hline 4 & - & 1.7 \\
\hline 5 & - & 0.1 \\
\hline 6 & 25 & 0.4 \\
\hline 7 & 38 & 1.8 \\
\hline 8 & - & 0 \\
\hline 9 & 67 & 5.0 \\
\hline 10 & - & 0 \\
\hline
\end{tabular}

Using the US-average industrial power cost of $0.0738 \$ / \mathrm{kWh}$, the approximate cost of electrodisinfection treatment using AC was calculated. Results for selected experiments are presented in Table 6.

The highest AC-treatment cost shown in Table 6 corresponds to the only AC electrodisinfection experiment that can be considered significant in terms of disinfection efficiency. This amount is substantially larger than those obtained for comparable DC electrodisinfection experiments, as shown in Table 4.

The results so far presented are an indication of the high efficiency of DCelectrodisinfection, which, in most cases, is close to $100 \%$.

Although the mechanisms for electrodisinfection with DC are not completely understood, it is reasonable to assume that chlorine is one of the oxidation agents contributing to wastewater disinfection given that a measurable amount of free chlorine is generated during treatment. However, as indicated previously, other disinfectants like hydrogen peroxide, ozone and hydroxyl radical might be produced, as described by equations 4,5 , and 6 .

A strong correlation between the amount of DC electrical current applied $(\mathrm{C} / \mathrm{L})$ and the amount of free residual chlorine generated was observed in the case of bipolar operation with 4 electrode plates. A non-linear regression analysis of the data yields the following exponential equation with a coefficient of determination $\mathrm{R}^{2}=$ 0.964 :

$$
C l_{2, F}=0.0326 e^{0.008404 C}
$$

where $\mathrm{Cl}_{2, \mathrm{~F}}$ is the free chlorine concentration, in $\mathrm{mg} / \mathrm{L}$, and $\mathrm{C}$ the current applied in coulo $\mathrm{mb} / \mathrm{L}$.

No significant temperature increase was observed when DC was used. On average, water temperature increased from room temperature $\left(23^{\circ} \mathrm{C}\right)$ to around $25^{\circ} \mathrm{C}$ or less.

Comparison of the results from DC and AC experiments highlights a substantial difference in power requirements between these two technologies to generate similar concentrations of free and total chlorine. When using DC, current intensity was between 0.3 and $0.5 \mathrm{~A}$ and voltage was between 40 and $65 \mathrm{~V}$. During treatment, water temperature changed by no more than $2^{\circ} \mathrm{C}$. On the other hand, in experiments with $\mathrm{AC}$, temperature increase was significant, and as much as $42^{\circ} \mathrm{C}$, in the case of run 9 .

The most important difference between $\mathrm{AC}$ and DC arises from the disinfection efficiency provided by similar concentrations of free and total chlorine. Using DC, the coliform removal was close to $100 \%$ with free and total chlorine concentrations of $0.06 \mathrm{mg} / \mathrm{L} \mathrm{Cl}_{2}$ and $0.142 \mathrm{mg} / \mathrm{L}$ $\mathrm{Cl}_{2}$, respectively. With $\mathrm{AC}$, and with concentrations of free and total chlorine of 0.152 $\mathrm{mg} / \mathrm{L} \mathrm{Cl}_{2}$ and $0.342 \mathrm{mg} / \mathrm{L} \mathrm{Cl}_{2}$, the number of CFUs was too numerous to count. Having a high disinfection efficiency with such a small concentrations of total and free chlorine when using DC, while having little or no disinfection when using $\mathrm{AC}$ even in the presence of larger amounts of chlorine, indicates that disinfection is being driven only in part by chlorine, but mostly by other oxidizing species, as supported by research conducted by several other investigators $[10,11$, 13]. Relevant to the discussion is the fact that a high volume of gas $\left(\mathrm{H}_{2}\right.$ and $\left.\mathrm{O}_{2}\right)$ was formed inside the reactor when using DC, which made it difficult to stabilize the flow due to the gas bubbles flowing with the liquid.

Table 6. Power consumption and treatment cost of selected AC electrodisinfection experiments

\begin{tabular}{|l|l|l|l|l|l|l|}
\hline Run & $\begin{array}{l}\text { Flow } \\
{[\mathrm{m} / \mathrm{min}]}\end{array}$ & $\begin{array}{l}\text { Voltage } \\
{[\mathrm{V}]}\end{array}$ & $\begin{array}{l}\text { Current } \\
{[\mathrm{A}]}\end{array}$ & $\begin{array}{l}\text { Log } \\
\text { removal }\end{array}$ & $\begin{array}{l}\text { Power } \\
{[\mathrm{kW}]}\end{array}$ & Cost $\left[\mathrm{Sm} \mathrm{m}^{3}\right]$ \\
\hline 3 & 33.33 & 55 & 2.66 & 1.4 & 0.146 & 5.40 \\
\hline 7 & 23 & 23.83 & 2.65 & 1.8 & 0.063 & 4.31 \\
\hline 9 & 26 & 39.9 & 3.38 & 5.0 & 0.135 & 6.37 \\
\hline
\end{tabular}

Gas evolution could be handled in large-scale reactors by providing safe gas release systems with appropriate gas release valves. 
When working with DC, the polarity of the electrodes does not change, whereas with alternating current, the charge changes from positive to negative 60 times per second. This might be one of the reasons why it appears that water electrolysis was not happening during any of the experiments performed in this research. Since oxidation and reduction occur in the vicinity of the anode and cathode respectively, it is possible that the change in electrode polarity was interfering with the formation of hydrogen and oxygen gases, generating micro volumes that were not detectable by simple inspection. In addition, precipitation of substances on the electrode surface will not occur when working with alternating current. This was verified each time the reactor was cleaned by inspecting the electrodes. The only thing that was found in the reactor was a little layer of settled solids from the wastewater, no substance was found attached to the electrodes. However, when inspecting the electrodes after the use of direct current, a white calcium carbonate precipitate was found attached to the electrodes, as found by other researchers [16].

The 5 log removal obtained in run number 9 with AC was clearly the result of thermal disinfection, or a significant increase in water temperature in the reactor during treatment, and not of chlorine- or hydro xyl radical-driven disinfection. Such a temperature increase was the result of the high voltage and current applied to the electrodes. The cost of AC disinfection per $\mathrm{m}^{3}$, as calculated for run 9, would be approximately $\$ 6.37$, while the cost of DC disinfection would be only $\$ 0.070$ per $\mathrm{m}^{3}$.

As indicated before, electrochemical disinfection is an emerging alternative to conventional chlorination processes. While some researchers believe that chlorine is responsible for disinfection, others believe that reactive oxygen species such as hydrogen peroxide and hydroxyl radicals are the actual disinfecting agents. Several researchers have reported the presence of hydroxyl radicals as well as good degrees of disinfection when alternating current was used for electrochemical disinfection. However, based on the results presented herein, it is the opinion of the authors that DC electrodisinfection is not only more efficient than its AC counterpart, but also a valid alternative to conventional chlorination.

\section{CONCLUSIONS}

Iridium-oxide-coated titanium is a very stable electrode material that can be used for electrodisinfection of secondary wastewater effluents. Using cheaper and less stable materials, such as stainless steel, is not a viable option due to water contamination with ferric hydroxide. In an electrodisinfection reactor equipped with this type of electrodes, water disinfection can be achieved even in the presence of low chloride concentrations, as is the case in the present research (average $\mathrm{Cl}^{-}=150 \mathrm{mg} / \mathrm{L}$ ).

Given the fact that during electrodisinfection treatment with DC chlorine generation was low, and therefore total and free chlorine concentrations in the treated effluent were also low, effluent de-chlorination might not even be necessary or, in the worst-case scenario, it would not be as costly as with conventional chlorination methods. This would all depend on the discharge regulations applicable to the particular wastewater discharge.

The following design criteria, derived from the findings presented herein, can be used as foundation for future research looking to expand on DC and AC electrodisinfection feasibility as a large-scale disinfection technology:

- Bipolar electrode configuration outperforms monopolar configuration.

- Recommended operating parameters for DC electrodisinfection reactors:

○ Energy input, $9.5 \times 10^{-4} \mathrm{kWh} / \mathrm{L}$.

○ Current, 0.3 A

- Current density, $30 \mathrm{~A} / \mathrm{m}^{2}$

○ Charge input, $55 \mathrm{C} / \mathrm{L}$

- Minimum retention time of 5 minutes.

In general, electro-disinfection using DC is applicable for secondary effluent disinfection and could be considered as a possible replacement of conventional chlorination treatments. Among its advantages, the following can be highlighted: low operational cost, almost no moving parts, low maintenance requirements, and there is no need to deal with handling and transportation of chemicals like $\mathrm{Cl}_{2}$ or sodium hypochlorite.

\section{ACKNOWLEDGMENTS}

Jeffers on Parish Department of Sewerage provided funding to conduct the experiments described herein. The unconditional support and assistance provided by the Marrero Wastewater Treatment Plant Superintendent, Mr. Ronald Huffman, is gratefully acknowledged.

\section{REFERENCES}

[1] Rajeshwar, K., and Ibáñez, J., Environmental Electrochemistry: Fundamentals and Applications in Pollution Abatement. (Academic Press., San Diego, CA, 1997).

[2] Ibáñez, J., Electrochemistry Encyclopedia (http://electrochem.cwru.edu/ed/encycl/).

Department of Chemistry and Chemical Engineering, Mexican Microscale Chemistry Center, Iberoamericana University. Mexico D.F., Mexico, 2004). 
[3] Vik, E.A., Carlson, D.A., Eikum, A.S., and Gjessing, E.T., Electrocoagulation of Potable Water. Water Research. 18 (11), 1984, 1355-1360.

[4] Kraft, A., Electrochemical water disinfection: a short review. Platinum metals review 52 (3) 2008, 177185.

[5] Lacasa, E., Tsolaki, E., Sbokou, Z., Rodrigo, M.A., Mantzavinos, D., and Diamadopoulos, E.,. Electrochemical disinfection of simulated ballast water on conductive diamond electrodes, Chemical Engineering Joumal, 223, 2013, 516-523.

[6] Huang, X., Qu, Y., Cid, C.A., Finke, C., Hoffmann, M.R., Lim, K., and Jiang, S.C., Electrochemical disinfection of toilet wastewater using wastewater electrolysis cell, Water Research, 92, 2016, 164 172.

[7] Snoeyink, V.L, and Jenkins, D., Aquatic Chemistry (Wiley, New York, NY, 1980).

[8] Saha, J., and Gupta, S.K., Electrochlorinat or - An Advanced Disinfection System for Drinking Water Supply, Discovery, 41(188), 2015, 86-92.

[9] McCraven, E. K., Electro-disinfection of Ballast Water. MS thesis. University of New Orleans, New Orleans, LA, USA, 2009.

[10] Park, J., Lee, M. S., Han, D. W., Lee, D. H., Park, B. J., Lee, I.S., Uzawa, M., Aihara, M., and Takatori, K., Inactivation of Vibrio parahaemolyticus in Effluent Seawater by Alternating-Current Treatment. Applied and Environmental Microbiology 70 (3) 2004, 1833-1835.
[11] Johnstone, P. T., and P. S. Bodger, Disinfection of deionised water using AC high voltage. IEE Proceedings-Science, Measurement and Technology 147 (3) 2000, 141-144.

[12] Barashkov, N. N., Eisenberg, D., Eisenberg S., Shegebaeva, G. Sh., Irgibaeva, I. S., and Barashkova, I. I. 2010. Electrochemical Chlorine-Free AC Disinfection of Water Contaminated with Salmonella Typhimurium Bacteria. Russian Joumal of Electrochem istry 46 (3) 2010, 320-325.

[13] Reimanis, M., L. Mezule, J. Ozolins, J. Malers, and T. Juhna, Drinking Water Disinfection with Electrolysis, Latvian Joumal of Chemistry, 4, 2012, 296-304. DOI: 10.2478/v 10161-01 2-0016-9.

[14] Pulido, M., Evaluation of an Electro-Disinfection Technology as an Alternative to Chlorination of Municipal Wastewater Effluents, MS Thesis, University of isper New Orleans, New Orleans LA, USA, 2005.

[15] Rincon, G.; La Motta, E.; and Mickler, B. Kinetics of Electrocoagulation of Hexane Extractable Materials in Artificial Bilge Water Treatment. Joumal of Ship Production and Design. 29 (1), 2013, 1-9.

[16] Kraft A., Wünsche M., Stadelmann M., Blaschke M., "Electrochemical water disinfection. Part II: Hypochlorite production from potable water, chlorine consumption, and the problem of calcareous deposits." Journal of Applied Electrochemistry. 29, $1999,895-902$. 